\title{
INCIDENCE AND CONCENTRATION OF AFLATOXIN B1 AND OCHRATOXIN A ON BROILERS RATION IN DAKAHILA GOVERNORATE EGYPT
}

\author{
ELALFY M MAHMOUD ${ }^{1}$ and ABDEIN M MOHAMED ${ }^{2}$ \\ ${ }^{1}$ Lecturer of Forensic Medicine and Toxicology Faculty of Veterinary Medicine Mansoura University \\ ${ }^{2}$ Researcher of National Agricultural Research Institute Cairo
}

Received: 8 December 2015; Accepted: 19 January 2016

\begin{abstract}
Mycotoxins consider as toxic secondary metabolites secreted from fungi which grow in certain condition of temperature and humidity. Now in our area, there is continuous change in climatic condition from year to another so we need to monitor level of mycotoxins in poultry ration regularly. Forty five samples of poultry rations collected from broiler chicken farms of Dakhalia Governorate and were analyzed by HPLC-UV. The present study showed that incidence of aflatoxin B1 (AFB1) and ochratoxin A were $64 \%$ and $50 \%$ in starter ration respectively and in finishing one were $52 \%$ and $45 \%$ for both aflatoxin B1 and ochratoxin A respectively. The concentration of aflatoxin B1 on poultry ration under analysis ranged from 0.5 to $62 \mathrm{ppb}$ while ochratoxin $\mathrm{A}$ level ranged from 3 to $52 \mathrm{ppb}$. Additionally, the mean values of aflatoxin B1 and ochratoxin A in strater ration were $17.22 \pm 20$ and $22.9 \pm 17.33$ respectively and in finishing ration were $9 \pm 10.04$ and $13.8 \pm 13$ respectively. In other word, these value of both mycotoxin is quite similar or low than the maximum european permissible limit of aflatoxin B1 (20 ppb) and for ochratoxin A (100 ppb).
\end{abstract}

Key words: Aflatoxin B1, Ochratoxin A, Broilers Ration, Dakahila Governorate, Egypt.

\section{INTRODUCTION}

Mycotoxins are toxic secondary metabolite of molds produced mainly by Fusarium, Aspergillus and Penicillium species found on feed stuff, particularly cereals. Food contamination with mycotoxins consider a matter of great concern as they may cause different harmful effects in animals varying from immune suppression, estrogenic or neurotoxin effects and may have lethal effect in severe cases Leung et al. (2006).

Mycotoxins have harmfull effect on both health and productivity in almost all species of domestic animals including poultry. In general, mycotoxicosis results in decrease feed intake, reduce feed conversion, decrease in production and subsequently increased susceptibility to various infections based on the type of toxins ingested (Xue et al., 2010).

Striet et al. (2012) found that mycotoxins in combination may exert synergetic, additive or antagonistic effects. Additionally, co-occurrence of aflatoxin and ochratoxin exerts their toxic effects synergistically. These effects could be more lethal even at low concentration of mycotoxins (Boermans and Leung, 2007).

Corresponding author: ELALFY M MAHMOUD

E-mail address: dr_melalfym@yahoo.com

Present address: Lecturer of Forensic Medicine and Toxicology Faculty of Veterinary Medic Research Institute, Mansoura University.
Rajamalar and Ravikumar (2014) reported that the storage of animal feeds was responsible of increase microbial favorable conditions. So obligatory precautions of preventing contamination of dried and stored animal feeds must be carried out in order to reduce levels of mycotoxin occurrence on animals feeds.

The intake of feed contaminated by ochratoxin also represents a potential risk for animal health and a food safety issue due to the transfer of the toxin through the food chain to humans. (Battacone et al., 2010).

European Union stated that no feed contained ochratoxin above the acceptable level on poultry finished feed. On the other hand, there was a number of samples contained aflatoxin above the acceptable limit (Ghulam et al., 2014). Thus, restricted control measures should be considered to ensure safe poultry for human consumption.

Moreover, Ghulam et al. (2014) found that corn, cotton seed meal, sunflower meal, and cotton gluten meal were highly contaminated with aflatoxin. While ochratoxin was determined to be high in feed ingredients more than finished feed samples with an overall incidence of $50 \%$. Maximum level of ochratoxin level was found to be more on corn gluten meal than other food ingredient for poultry feed. 
The incidence of aflatoxin in analyzed samples of different feed ingredients varied from 0 to $94 \%$. while ochratoxin A was present in $67 \%$ of samples in Sudan and in $100 \%$ of Nigerian samples. Additionally, the major levels found for Btrichothecenes, zearalenone and aflatoxin were 2786 , 135 and $213 \mathrm{ng} \mathrm{g}^{1}$, respectively and no ochratoxin was detected in a broiler feed sample from Egypt (Rodriguesa et al., 2011).

Ali and Anwer (2009) found that the presence of aflatoxin B residues in hens' eggs might occur at relatively low level under conditions of long term exposure of laying hens to low level of aflatoxin in naturally contaminated ration at $50 \mu \mathrm{g} / \mathrm{kg}$ with reduction in feed intake.

In the United States, the Food and Drug Administration, has established a tolerance of 20 ppb of aflatoxin for human foods other than milk, but European markets are striving for a lower Codex importation standard of 2 ppb (Abbas, 2005).

In one of egyptian record of mycotoxins in Gharbia Governorate, Fahmy et al. (2015) found that aflatoxin were higher than the maximum permissible limit in most samples (20 ppb) while the mean concentration of ochratoxins in feed samples was $43.58 \mathrm{ppb}$, and $2.22 \%$ of samples were higher than the MPL (100 ppb)

The rational of this study to explore incidence and the concentration of aflatoxin B1 and ochratoxin A in broiler poultry feeds.

\section{MATERIALS and METHODS}

Forty five samples of broiler chicken starter and finishing rations were collected from private poultry farms at Dakahlia Governorate during summer season 2014. The samples were collected randomly in special bags from broiler poultry farm which kept separately until taken to laboratory for aflatoxin B and ochratoxin A extraction and analysis.

\section{Extraction of the samples}

$10 \mathrm{gm}$ of each sample was extracted and prepared for detection of aflatoxin and ochratoxin using a mixture of acetonitrile: water (80:20) and cleaned up by dispersive liquid-liquid microextraction which is a very economical, fast and sensitive method which described by Ansarin and Mahboob (2015). The samples were blinded at high speed for one minute. The extract was poured in fluted filter paper and the filtrate was collected in clean beaker.

\section{Extract dilution}

The filtrated extract was diluted with $40 \mathrm{~mL}$ diionized water, mixed well, then filtration through microfibre filter and the filtrate was collected in a clean beaker or directly into glass syringe barrel.

\section{Column chromatography for aflatoxin}

The diluted extract was passed $(2 \mathrm{~mL}=0.2 \mathrm{~g}$ sample equivalent) completely through AflaTest-p affinity column at a rate of about 1-2 drops/second until air comes through column. $5 \mathrm{~mL}$ of diionzed water (Sigam-aldrich company) was pass through the column at a rate of 2 drops/second, this step was repeated once or more until air comes through column. Elute affinity column by passing $1.0 \mathrm{~mL}$ HPLC grade methanol through column at OchraTest affinity column at a rate of about 1-2 drops/second until air comes through column. $10 \mathrm{~mL}$ of mycotoxin wash buffer were pass through the column at a rate of about 1-2 drops/second until air comes through column. $10 \mathrm{~mL}$ of diionzed water was pass through the column at a rate of 2 drops/second. Elute affinity column by passing $1.5 \mathrm{~mL}$ OchraTest eluting solution through column at a rate of 1-2 drops/second, this elute must be completely collected in a glass cuvette, mix well and the cuvette was placed in a calibrated fluorometer. Ochratoxin was quantified by HPLC-UV (molel 1100-21) without need for any complex derivatisation in samples to enhance the detection (Amirkhizi et al., 2015).

\section{RESULTS}

The present survey (Table 1) found that incidence of both aflatoxin and ochratoxin were $64 \%$ and $50 \%$ for both aflatoxin and ochratoxin respectively in starter ration and in finishing one were $52 \%$ and $45 \%$ respectively.

Moreover, the mean values of aflatoxin B1 and ochratoxin $A$ in strater ration were $17.22 \pm 20$ and $22.9 \pm 17.33$ respectively and $9 \pm 10.04$ and $13.8 \pm 13$ in finishing ration respectively (table 2 ).

Finally, the level of aflatoxin on poultry ration under experiment was ranged from $0.5 \mathrm{ppb}$ to $62 \mathrm{ppb}$ with the mean value of $17.22 \mathrm{ppb}$ and ranged from 5.4 to $40 \mathrm{ppb}$ with the mean value of $9 \mathrm{ppb}$ in finishing ration. While ochratoxin level was ranged from 3 to $52 \mathrm{ppb}$ with the mean value of $22.9 \mathrm{ppb}$ in starter ration and ranged from 5.4-35 ppb with the mean value of $13.8 \mathrm{ppb}$ in finishing ration (table 1and table 2). 
Table1: Show the incidence and range of aflatoxin B1and ochratoxin A on broilers ration.

\begin{tabular}{ccccc}
\hline & \multicolumn{2}{c}{ Incidence } & \multicolumn{2}{c}{ Range (ppb) } \\
\cline { 2 - 5 } & Aflatoxin B1 & Ochratoxin A & Aflatoxin B1 & Ochratoxin A \\
\hline Starter ration & $64.00 \%(16 / 25)$ & $52(13 / 25$ & 0.5 to 62 & $3-52$ \\
\hline Finishing ration & $50.00 \%(10 / 20)$ & $45(9 / 20)$ & 5.4 to 40 & $5.4-35$ \\
\hline
\end{tabular}

Table 2: Show mean of concentration ( $\mathrm{ppb}$ ) of aflatoxin B1 and ochratoxin A ppb on broilers ration.

\begin{tabular}{ccc}
\hline Type of ration & Aflatoxin B1 & Ochratoxin A \\
\hline starter & $17.22 \pm 20$ & $22.9 \pm 17.33$ \\
\hline Finishing & $9 \pm 10.04^{*}$ & $13.8 \pm 13^{*}$ \\
\hline
\end{tabular}

\section{DISCUSSION}

The aflatoxin and ochratoxin on poultry ration could be pass to human food through chicken meats or eggs and consider hazardous on both poultry production and human health (Bryden, 2012 and Zafar et al., 2014).

As mycotoxins are one of the major risk element on poultry productivity and also product quality, control of their impact is serious (Oguz, 2011). The need of continuous detection of these toxins in chicken ration, meat and eggs consider important.

This result indicated that Aflatoxin B1 and ochratoxin A were of high incidence and its were significantly increase in starter ration when compared with finishing one (Table 1,2). This result agree with Rodriguesa et al. (2011) who found that the presence of aflatoxin B1 in monitored poultry feed samples varied from 0 to $94 \%$ while Ochratoxin A was present in $67 \%$ of samples in Sudan and in $100 \%$ of Nigerian samples. Moreover, only on Egypt for aflatoxin our result agree with Rodriguesa et al. (2011) who reported that aflatoxin and no ochratoxin were detected in a broiler feed sample collected from Egypt. Additionally, our result agree with ThirumalaDevi et al. (2002) who found that $38 \%$ of the samples were contaminated with aflatoxins and $6 \%$ with ochratoxin A. The incidence scores of aflatoxin contamination in excess of 10 microgram $/ \mathrm{kg}$ were 41 of 95 for maize, 18 of 30 for mixed feeds of Indian poultry.

Notably, our result agree with value of both mycotoxin maximum permissible limit of aflatoxin B1 (20 ppb) and for ochratoxins (100ppb) for European standard. And disagree with Fahmy et al. (2015) who found that aflatoxin in Gharbia Governorate were higher than the maximum permissible limit in most broiler feed samples (20 $\mathrm{ppb}$ ) while the mean concentration of ochratoxins in feed samples was $43.58 \mathrm{ppb}$, and $2.22 \%$ of samples were higher than the MPL (100 ppb).
Aflatoxin and ochratoxin are the most common mycotoxins in poultry feed (Pattison et al., 2008). We need to monitor the amount of mycotoxins in our area regularly in order to avoid hazardous effect of these mycotoxins on poultry production. Dietary exposure of broiler hens to $10 \mathrm{ppm}$ of AFB resulted in embryonic mortality and reduced the immunity in the progeny chicks. Embryonic exposure with aflatoxins resulted in long-term depression of the immune function in chickens (Resanovic $\mathrm{R}$ et al., 2009). Growth inhibition is linked with malabsorption syndrome, as confirmed by the presence of hypocarotenoidemia. The minimum amount of ochratoxin also causes reduced bone firmness and poor pigmentation. Acutely intoxicated birds are depressed, dehydrated and often polyuric and die in acute renal failure. Survivors will be poorly feathered, have delayed sexual maturity, increased clotting times, anaemia and immunosuppression.(Resanovic R et al., 2009). The interaction between aflatoxin B and ochratoxin A was noted experimentally on broiler chickens as both mycotoxins were decreased significantly the growth rate and increased the mortality through induced nephropathy even at very low levels (Huff and Doerr, 1981 and Raja and Balachandran, 2009).

Finally, the present study showed that aflatoxin B1 and ochratoxin A were detected in poultry ration with low level as similar as European standard but of high incidence in starter ration than finishing ration of broiler chicken.

\section{REFERENCES}

Abbas, H. (2005): Aflatoxin and Food Safety, Taylor and Francis v 10 (2) pg, 254, 261.

Amirkhizi Behzad; Seyed Rafie Arefhosseini; Masoud Ansarin and Mahboob Nemati (2015): Aflatoxin B1 in eggs and chicken livers by dispersive liquid-liquid microextraction and HPLC. Food Additives and Contaminants: Part B: Surveillance Volume 8, Issue 4, pages 245- 
249.

Ansarin and Mahboob Nemati (2015): Aflatoxin B 1 in eggs and chicken livers by dispersive liquid-liquid microextraction and HPLC. Food Additives and Contaminants: Part B: Surveillance V 8, (4) pages 245-249.

Battacone, G..; Nudda, A. and Pulina, G. (2010): Effects of Ochratoxin A on Livestock Production. Toxins 2, 1796-1824; doi: 10.3390/toxins 2071796.

Boermans, H.J. and Leung, M.C.K. (2007): Mycotoxins and the pet food industry: Toxicological evidence and risk assessment. Intl. J. Food Mi(crobiol. 119, 95-102.

Bryden, W.L. (2012): Mycotoxin contamination of the feed supply chain: Implications for animal productivity and feed security. Animal Feed Science and Technology, 173, 134e158.

Fahmy Nahla Elsayed, Eltholth Mahmoud Mohamed, Mohamed Radi Ali, ElTras Wael Fawzy and El-Midany Samy Abd El-Aziz (2015): Management of Poultry Farms and the Likelihood of Contamination of Poultry Feed with Mycotoxins in Gharbia Governorate, Egypt. World Vet. J., 5(4): 51-58

Ghulam Fareed; Sohail Hassan; Khan Muhammad; Ashraf Anjum and Naveed Ahmed (2014): Determination of Aflatoxin and Ochratoxin in poultry feed ingredients and finished feed in humid semi-tropical environment J. Adv. Vet. Anim. Res., 1(4): 201-207.

Huff, WE. and Doerr, JA. (1981): Synergism between aflatoxin and ochratoxin $\mathrm{A}$ in broiler chickens. Poult Sci. Mar; 60(3): 550-5.

Zafar Shahzad Sonia Nisar; Muhammad Rafique Asi and S. Jinap b,d, (2014): Natural incidence of aflatoxins, ochratoxin $\mathrm{A}$ and zearalenone in chicken meat and eggs. Food Control 43 98e 103

Leung, MCK.; Diaz, LG. and Smith, TK. (2006): Mycotoxins in pet food: a review on world wide prevalence and preventative strategies. J. Agric. Chem. 54, 9623-9635.

Oguz, H. (2011): A review from experimental trials on detoxification of aflatoxin in poultry feed. Eurasian J. Vet. Sci., 27 (1): 1-12.

Pattison, M.; McMullin, P.; Bradbury, J. and Alexander, D. (2008): Poultry Diseases (Sixth Edition), Chapter 38, pages 435-442;

Rajamalar, P. and Ravikumar, K.A. (2014): Study on the incidence and nature of aflatoxin from animal feeds. SIRJ-AZASN Volume 1 Issue 1.

Resanovic, R.; Ksenija, N.; Nesic, V.; Palic, T. and Jacevic, $V$. (2009): Mycotoxins in poultry production, Proc. Nat. Sci, Matica Srpska Novi Sad, 116, 7-14.

Rodriguesa, I.; Handland, J.; Binder E.M. (2011): Mycotoxin occurrence in commodities, feeds and feed ingredients sourced in the Middle East and Africa. Food Additives and Contaminants: Part B Vol. 4, No.3, September, 168-179.

Raja Kumarl and Chidambaram Balachandran (2009): Histopathological changes in broiler chickens fed afl atoxin and cyclopiazonic acid. veterinarski archiv, 79 (1), 31-40.

Aly Salwa, A. and Anwer, W. (2009): Effect of Naturally Contaminated Feed with Aflatoxins on Performance of Laying Hens and the Carryover of Aflatoxin B Residues in Table Eggs. Pakistan Journal of Nutrition 8 (2): 181-186.

Streit, E.; Gerd, S.; Panagiotis, T.; Eleni, T.; Daniela, M.; Ionelia, T.; Cristina, T.; Anca, N.; Iuliana, A.; Olivier, P. and Isabelle, PO. (2012): Current situation of mycotoxin contamination and co-occurrence in animal feed-focus on Europe. Toxins. 4, 788-809.

Thirumala-Devi, K1.; Mayo, MA. and Reddy, DV. (2002): Occurrence of aflatoxins and ochratoxin A in Indian poultry feeds. J Food Prot. Aug; 65(8): 1338-40.

Xue, C.Y.; Wang, G.H.; Chen, F.; Zhang, X.B. and Cao, Y.C. (2010): Immunopath-ological Effects of Ochratoxin A and T-2 Toxin Combination on Broilers. Poult. Sci., 89: 1162-1166.

\section{نسب تواجد وتركيز الأفلاتوكسين ب ا والاكراتوكسين أ في علائق الاواجن بمحافظه الدقهليه \\ محمود محمد الالفي الحفناوي ، محمد محمد عابلين \\ Email:dr_melalfym@yahoo.com Assiut University web-site: www.aun.edu.eg}

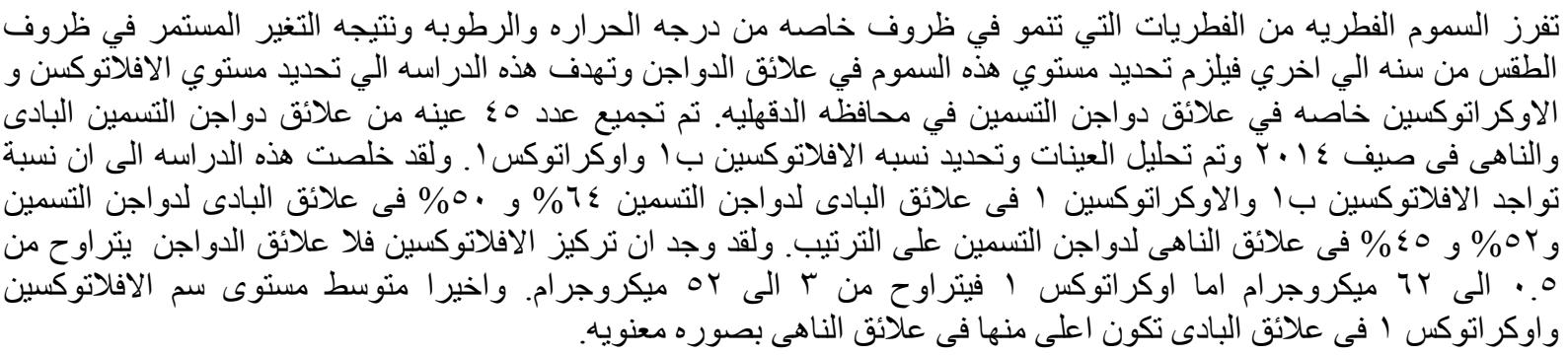

